\title{
Antimicrobial activity of novel mouthrinses against planktonic cells and biofilms of pathogenic microorganisms
}

\author{
Sladjana Malic ${ }^{1 *}$, Charlotte Emanuel ${ }^{2 \dagger}$, Michael AO Lewis ${ }^{2 \dagger}$ and David W Williams ${ }^{2 \dagger}$ \\ *Correspondence: S.malic@mmu.ac.uk \\ ${ }^{\dagger}$ These authors contributed equally to this work. \\ 'School of Healthcare Science, Manchester Metropolitan University, Manchester M1 5GD, UK. \\ ${ }^{2}$ School of Dentistry, College of Biomedical and Life Sciences, Cardiff University, Heath Park, Cardiff, CF14 4XY, UK.
}

\begin{abstract}
Background: Oral diseases pose major public health problems on a global scale. Such diseases have considerable impact on individuals and communities by causing pain and suffering, impairment of function and reduced quality of life. The objective of this study was to evaluate the antimicrobial activity of five mouthrinses against a variety of microorganisms associated with infections of the oral cavity and other body sites.

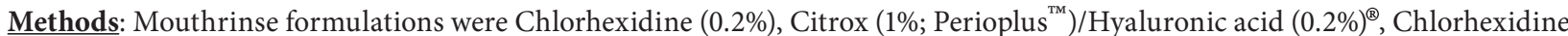
$(0.2 \%) /$ Citrox $\left(1 \%\right.$; Perioplus $\left.{ }^{\mathrm{TM}}\right)$, Chlorhexidine $(0.2 \%) /$ Phenoxetol $(0.1 \%)^{\circledR}$ and Citrox $\left(1 \%\right.$; Oralclens) ${ }^{\mathrm{TM}}$ (Oraldent Ltd; UK). The test microorganisms were the bacteria, Actinomyces viscosus ATCC 1598; Actinomyces odontolyticus NCTC 9935, Clostridium difficile R8651, Prevotella intermedia NCTC $13070^{\mathrm{T}}$, Prevotella denticola R20771, Porphyromonas gingivalis NCTC $11834^{\mathrm{T}}$, Streptococcus gordonii ATCC $10558^{\mathrm{T}}$, Streptococcus sanguinis NCTC 7863, and the fungi, Candida albicans ATCC 90028, Candida dubliniensis CD36, Candida krusei ATCC 6258, Candida glabrata ATCC 2001, Candida tropicalis ATCC 750 and Candida parapsilosis ATCC 22019. Determination of mouthwash antifungal and antibacterial properties was done using a microtitre plate assay. In vitro biofilms were constructed using 96-well plates and exposed to a range of mouthrinse concentrations. The minimum biofilm eradication concentration (MBEC) was established by examining subsequent re-growth of biofilm cells. Results were compared with the minimum inhibitory concentrations (MICs) obtained for planktonic cells cultured in 96-wells plates in various mouthrinse concentrations.

Results: Planktonic cells of aerobic microorganisms were inhibited by all mouthrinses at concentrations $\leq 2 \%$ (v/v) of the stock preparation. Chlorhexidine $(0.2 \%) / \operatorname{Citrox}(1 \%)^{\mathrm{TM}}$ had the highest antimicrobial activity, followed by Citrox $(1 \%)^{\mathrm{TM}}, 0.2 \%$ Chlorhexidine, Chlorhexidine $(0.2 \%)$ /Phenoxetol $(0.1 \%)^{\circledR}$ and Citrox $(1 \%) /$ Hyaluronic acid $(0.2 \%)^{\circledR}$. Some anaerobic bacteria (Actinomyces odontolyticus, Clostridium difficile, Prevotella intermedia) exhibited higher MICs for all 5 mouthwashes. There was a noticeable increase (up to 16 -fold) in tolerance to the mouthwashes by the majority of aerobic microorganisms when the minimum biofilm eradication concentration was compared to the minimum inhibitory concentration.

Conclusion: The results highlight enhanced antimicrobial activity using a combined preparation of Chlorhexidine/Citrox compared with Chlorhexidine alone.
\end{abstract}

Keywords: Periodontal diseases, dental caries, oral candidosis planktonic microorganisms, biofilm, antimicrobial activity, Citrox

\section{Introduction}

Dental caries and periodontal diseases are significant health problems of humans [1], and arise irrespective of socioeconomic class, although they are more prevalent in deprived populations [2]. Dental caries affects $60-90 \%$ of children in industrialised countries [3] and approximately 10-15\% of adults are affected by severe periodontal disease. These plaque-mediated diseases lead to premature dental exfoliation and have a significant impact on the quality of life [4,5]. Periodontal disease has been also implicated with systemic chronic diseases such as cardiovascular disease [6].

An important factor in both caries and periodontal disease is the oral microflora and it is the biofilms produced by these organisms that are at the centre of disease pathogenesis. Thus, biofilm control by mechanical debridement and use of adjunctive antimicrobials is of utmost importance in prevention of plaque-mediated diseases. Typical adjuncts to oral hygiene and prevention of the aforementioned diseases have been the use of mouthwashes and toothpastes containing antimicrobial components such as triclosan and Chlorhexidine. Both these components are classed as biocides as they target multiple sites to achieve antimicrobialeffects. Triclosan (5-Chloro-2(2,4dichlorophenoxy)phenol) is a halogenated phenol, and a non-ionic broad spectrum antimicrobial that has multiple uses including being an active component in detergents, clothing, toothpastes, and mouthwashes [7]. Concerns regarding triclosan use in 'everyday products' has been raised, as over exposure of microorganisms to this agent might propagate resistance and indeed there has been evidence of low-level resistance in Staphylococcus aureus $[1,8]$. Triclosan has also been 
Malic et al. Microbiology Discovery 2013,

http://www.hoajonline.com/journals/pdf/2052-6180-1-11.pdf

doi: $10.7243 / 2052-6180-1-11$

detected in sediment, soils, and aquatic species [7] and recent environmental concerns have been raised leading to some calls for its use to be limited [7-11]. Chlorhexidine has also been associated with adverse effects including mucositis, altered taste, and staining of dental tissues and restorations $[\mathbf{1 , 1 2}]$. Such undesirable reactions to Chlorhexidine have resulted in calls for modified clinical practice $[13,14]$ and along with patient preferences have been the drivers for research into alternative mouthwashes/remedies for oral care.

For centuries, plant products have been used as treatments for diseases, and more recently in the development of new drugs [13]. Previous studies have indicated the effective and efficient use of natural antimicrobials in inhibiting the oral microflora $[13,14]$. Citrox, is a soluble formulation of bioflavonoids, derived from citrus fruits, and this agent has antimicrobial activity against bacteria, fungi and viruses [15-18].

This present study investigated potential potentiation of antimicrobial activity through use of combinations of Citrox (1\%) with Chlorhexidine (0.2\%; Perioplus $\left.{ }^{\mathrm{TM}}\right)$, and Citrox (1\%)/ Hyaluronic acid $(0.2 \%)^{\circledR}$. To this end, reducing Chlorhexidine concentration may result in reduced side effects, whilst maintaining antimicrobial properties. Hyaluronic acid is a major component of collagen, and an important factor in wound healing, and thus could be significant in the treatment of periodontal disease [19]. Small molecular weight hyaluronic acid has also been found to induce expression of toll-like receptors, which are important components of the innate immune system [20]. Thus, the combination of Citrox with hyaluronic acid may provide both bactericidal and wound healing properties in vivo. Often, in vitro assessment of antimicrobial activity is performed only against planktonic cells, and these tend to be much more susceptible to antimicrobials than their biofilm counterparts. In this present study, we evaluated the antimicrobial activity of 5 different mouthrinses against 14 test strains including bacteria and Candida species, cultured both planktonically and as biofilms.

\section{Materials and methods}

Microorganisms investigated in this studywere Actinomyces viscosus (ATCC 1598), Actinomyces odontolyticus (NCTC 9935), Clostridium difficile (R865, clinical isolate), Prevotella intermedia (NCTC 13070'), Prevotella denticola (R20771), Porphyromonasgingivalis (NCTC 11834'), Streptococcus gordonii (ATCC 10558'), Streptococcus sanguinis (NCTC 7863), Candida albicans (ATCC 90028), Candida dubliniensis (CD36 [21]), Candida krusei (ATCC 6258), Candida glabrata (ATCC 2001) and Candida tropicalis (ATCC 750).

The bacteria Actinomyces viscosus ATCC 1598, Actinomycesodontolyticus NCTC 9935, Clostridium difficile R8651, Prevotella intermedia NCTC 13070', Prevotella denticola R20771 and Porphyromonas gingivalis NCTC $11834^{\top}$ were cultured under anaerobic conditions at $37^{\circ} \mathrm{C}$ on Fastidious Anaerobe Agar (FAA) and in Fastidious Anaerobe Broth (FAB). Streptococcus species were cultured aerobically at $37^{\circ} \mathrm{C}$ using Blood Agar
(BA) and Brain Heart Infusion Broth (BHI). Candida species were cultured aerobically at $37^{\circ} \mathrm{C}$ using Sabouraud Dextrose Agar (SDA) and Sabouraud Broth (SAB). All media was obtained from Lab M (International Diagnostics Group plc, Bury, UK) and prepared as per the manufacturer's instructions. Broths were not adjusted for $\mathrm{pH}$ or glucose content. All mouthrinses were provided courtesy of Oraldent Limited, UK.

\section{Minimum inhibitory concentration (MIC) determination for planktonic cells}

Microbial preparations of bacteria and Candida species were generated by overnight incubation, and adjusted to a turbidity equivalent to a MacFarland standard of 3.0. Serial dilutions of the test mouthrinses in the respective culture medium were prepared, resulting in a concentration range of $0.007 \%$ to $8 \%(\mathrm{v} / \mathrm{v})$ of the parent mouthrinses. A $100-\mu \mathrm{l}$ volume of each test dilution was then combined with $100 \mu$ l of microbial suspension. Negative controls of broth and bacterial suspensions without antimicrobial were also included. To the wells of 96 -well microtitre plates, $200 \mu$ of the preparations were added and incubated for 24 hat $37^{\circ} \mathrm{C}$, under the appropriate atmospheric conditions. Following incubation, the relative growth of the microbial species was estimated by recording the turbidity of wells using spectrophotometric absorbance at $620_{\mathrm{nm}}$. Absorbance readings were standardised using 'microbial-free' control mouthwash dilutions. The MIC was recorded as the lowest concentration of mouthwash that showed $\geq 80 \%$ reduction in absorbance compared to the controls without mouthrinses.

\section{Minimum Biofilm Eradication Concentrations(MBEC) for biofilms}

Suspensions of each microorganism (MacFarland standard 3.0) were incubated in the wells of a flat-bottomedmicrotitre plate for $24 \mathrm{~h}$ at $37^{\circ} \mathrm{C}$. BHI was used as the culture medium for bacteria, $F A B$ was used for culture of anaerobic bacteria and $\mathrm{SAB}$ for Candida; incubation was without agitation to allow formation of a biofilm. The medium was then removed by gentle aspiration and the biofilm washed with $100 \mu \mathrm{l}$ of phosphate buffered saline (PBS) to remove planktonic cells. Fresh medium containing test mouthrinse concentrations or negative control broth was added to the biofilms. Biofilms were then incubated for a further $24 \mathrm{~h}$ under the described conditions. The medium was subsequently removed by gentle aspiration and the biofilm washed with PBS. Fresh broth $(200 \mu \mathrm{l})$ was added and the biofilms were disrupted by repeated pipetting and agitation. The turbidity of the resuspended biofilm was observed by measuring the absorbance at $620_{\mathrm{nm}}$. Following a further incubation period of $6 \mathrm{~h}$, the absorbance at $620_{\mathrm{nm}}$ was once again recorded. The relative growth of the microorganisms was determined by the difference in absorbance over this $6 \mathrm{~h}$ period. The mean value was calculated from quadruplicate samples in each well and the MBEC recorded as the lowest concentration of 
Malic et al. Microbiology Discovery 2013,

Table 1a. Minimum inhibitory concentration \% (v/v) of mouthrinses against planktonic microorganisms.

\begin{tabular}{lccccc}
\hline & \multicolumn{5}{c}{ Minimum inhibitory concentration } \\
\% (v/v)
\end{tabular}

Sample A: Chlorhexidine Control (0.2\%).

Sample B: Citrox (1\%)/Hyaluronic acid $(0.2 \%)^{\circ}$.

Sample C: Chlorhexidine (0.2\%)/Citrox (1\%)-Perioplus ${ }^{\mathrm{Tu}}$.

Sample D: Chlorhexidine (0.2\%)/Phenoxetol $(0.1 \%)^{\circ}$.

Sample E: Citrox (1\%)-Oralclens ${ }^{\mathrm{Tn}}$.

Table 1b. Minimum biofilm eradication concentration \% (v/v) of mouthrinses against microorganisms grown in biofilms.

\begin{tabular}{lccccc}
\hline & \multicolumn{5}{c}{$\begin{array}{c}\text { Minimum Biofilm Eradication } \\
\text { Concentration \% (v/v) }\end{array}$} \\
\hline Mouthrinse & A & B & C & D & E \\
\hline Microorganism & & & & & \\
\hline C. albicans & 4 & $>4$ & 4 & $>4$ & 2 \\
C. dubliniensis & 2 & 4 & 2 & $>4$ & 4 \\
C. krusei & 2 & 1 & 0.5 & 2 & 0.5 \\
C. glabrata & 2 & 4 & 2 & 4 & 4 \\
C. parapsilosis & $>4$ & 4 & 1 & $>4$ & 1 \\
C. tropicalis & 2 & 4 & 2 & 4 & 4 \\
S. gordonii & 0.5 & 2 & 0.5 & 1 & 1 \\
S. sanguinis & 0.5 & 2 & 0.5 & 1 & 1 \\
A. odontolyticus & 0.25 & 1 & 0.125 & 0.5 & 0.25 \\
A. viscosus & 0.125 & 0.25 & 0.125 & 0.25 & 0.125 \\
C. difficile & 0.5 & 4 & 1 & 4 & 1 \\
P. denticola & 0.125 & 1 & 0.5 & 0.5 & 0.5 \\
P. gingivalis & 0.125 & 2 & 0.25 & 1 & 1 \\
P. intermedia & 0.25 & 4 & 0.063 & 0.125 & 0.125 \\
\hline Sanple A: Chlorh
\end{tabular}

Sample A: Chlorhexidine Control (0.2\%).

Sample B: Citrox $(1 \%) /$ Hyaluronic acid $(0.2 \%)^{\circ}$.

Sample C: Chlorhexidine $(0.2 \%) /$ Citrox (1\%)-Perioplus ${ }^{\mathrm{TM}}$.

Sample D: Chlorhexidine $(0.2 \%) /$ Phenoxetol $(0.1 \%)^{\oplus}$.

Sample E: Citrox (1\%)-Oralclens ${ }^{\mathrm{Tw}}$.

the test mouthwash that demonstrated a $\geq 80 \%$ reduction in absorbance compared to the control. All experiments were performed on 3 separate occasions.

\section{Results}

Minimum inhibitory concentrations for planktonic growth of the mouthrinses for the 14 test microorganisms are shown in Table 1a. Inhibition of planktonic cells of all aerobic microorganisms occurred with the 5 mouthrinses at concentrations $\leq 2 \%$ (v/v). Chlorhexidine (0.2\%)/Citrox (1\%; Perioplus $\left.{ }^{\mathrm{T}} \mathrm{M}\right)$ demonstrated highest antimicrobial activity against aerobic microorganisms, followed by Citrox (1\%; Oralclens) ${ }^{\mathrm{TM}}, 0.2 \%$ Chlorhexidine, Chlorhexidine $(0.2 \%) /$ Phenoxetol $(0.1 \%)^{\circledR}$ and Citrox (1\%)/Hyaluronic acid $(0.2 \%)^{\circledR}$. For anaerobic microorganisms, Actinomyces odontolyticus. Clostridium difficile and Prevotella intermedia had relatively high MICs against the 5 mouthwashes ( $\geq 4 \%(\mathrm{v} / \mathrm{v})$ ). Actinomyces viscosus, Prevotella denticola and Porphyromonas gingivalis had MIC ranging between $0.125 \%-1 \%(\mathrm{v} / \mathrm{v})$.

\section{Minimum Biofilm Eradication Concentrations(MBEC) for biofilms}

The recorded MBECs in the biofilm assay are shown in Table $\mathbf{1 b}$. In the case of aerobic species biofilms, there was a noticeable increased tolerance (MBEC values of up to 16-fold of the previous MIC values) for the majority of the tested microorganisms against all 5 mouthrinses formulations. The MBECs for anaerobic species were generally lower than for the aerobic species. Interestingly, for $A$. odontolyticus, $C$. difficile and $P$. intermedia the MBEC was lower than the MIC planktonic growth phase, a finding that could indicate relatively poor biofilm development.

\section{Discussion}

Oral disease is a worldwide health concern having significant impact on patient quality of life and function. Of further concern is that it is expected that the incidence of dental caries and periodontal disease will continue to increase as a result of the growing intake of sugars in the diet, tobacco use, and inadequate exposure to fluorides, and lack of access to dental care [22].

Increasing antibiotic resistance has promoted interest in the therapeutic use of non-conventional or alternative medicines and plant extracts $[\mathbf{1 3}, \mathbf{2 3 - 2 6 ]}$. It has been shown that naturally occurring biocides are effective in inactivating a variety of microorganisms by affecting multiple target sites and are therefore less prone to development of resistance compared to conventional antibiotics targeting specific bacterial sites $[\mathbf{2 7}, \mathbf{2 8}]$. There is great potential for the development of novel bioactive compounds, as there are approximately 500,000 plant species worldwide, of which only $1 \%$ have been phytochemically investigated [29].

Hooper et al., [13] previously tested two Citrox formulations against a range of oral microorganisms and reported MICs of $1 \%(\mathrm{v} / \mathrm{v})$ in planktonic and biofilm assays. Extracts from Citrus sudachi have also been observed to elicit antimicrobial 
Malic et al. Microbiology Discovery 2013,

http://www.hoajonline.com/journals/pdf/2052-6180-1-11.pdf

doi: 10.7243/2052-6180-1-11

activity against bacteria, including methicillin-resistant Staphylococcus aureus (MRSA) and Helicobacter pylori [16]. The relatively high inoculum used in this present study was employed to mimic the in vivo challenge of having to combat an established high level of microorganisms, as encountered in dental plaque, and was based on previous evaluations and thus would allow comparisons [13].

The results of this present study demonstrated the antimicrobial effects of 5 mouthrinse formulations on a range of oral microorganisms and C. difficile. Four of these mouthwash formulations contained Citrox, which is a combination of natural bioflavonoids. Three of these Citrox mouthrinses were supplemented with Chlorhexidine, hyaluronic acid or phenoxetol.

All test mouthrinses had substantial antimicrobial activity against aerobic planktonic microorganisms at concentrations $\leq 2 \%(\mathrm{v} / \mathrm{v})$ with a naerobic species generally less susceptible. This activity against planktonic cells is clearly important, as free-living microorganisms are abundant in saliva and provide the source of bacteria for colonization and subsequent biofilm formation on oral surfaces $[30,31]$. The inhibition of biofilm growth is widely recognised as being more problematic than that of planktonic cells. The reasons for this are multifactorial and complex. It has been suggested that the extracellular polymeric substance (EPS) that encases biofilm cells is a key component in limiting access of antimicrobial agents to the biofilm cells, possibly through charge mediated sequestration [32]. Alternatively, the biofilm cells themselves may exhibit different phenotypes, and some, may have reduced activity due to nutrient or gaseous limitations [33]. Since cells with reduced growth rates can be more resistant to many antimicrobials, this too could be a reason for enhanced tolerance. It was perhaps not surprising therefore to find that the antibiofilm activity of the mouthrinses against some species was on occasion up to 16 -fold higher their planktonic counterparts. Surprisingly however, the MBECs of anaerobic biofilms were frequently lower compared with the MICs for the planktonic counterparts. One caveat to consider was that the biofilm growth for anaerobic bacteria was relatively limited compared to that of the aerobes and this could explain the lower susceptibility compared to their planktonic equivalents. Anaerobic species often require nutrient rich media (e.g. FAB) for growth compared to aerobes and the former also exhibit much slower growth. It may be that the $24 \mathrm{~h}$ incubation used for biofilm formation was not sufficient for a robust biofilm growth of the anaerobes, rendering them more susceptible to the mouthrinses. It was also possible that the biofilms generated by the anaerobes could also have been less stable, which may have led to a loss of biofilm cells during the washing steps. To overcome this problem, future studies could incorporate longer incubation periods to allow biofilm formation and in addition, to incorporate artificial saliva into the model system to increase biofilm attachment, as well as utilising a more nutrient rich culture medium.

\section{Conclusions}

In conclusion, the results suggest that Chlorhexidine (0.2\%)/ Citrox (1\%; Perioplus ${ }^{\mathrm{TM}}$ ) had highest antimicrobial activity and use of this combination formulation was more effective than either of its constituent antimicrobial components used alone (Citrox or Chlorhexidine). The reason for this finding may be indicative of different targets of these antimicrobial components leading to an enhanced and possible synergistic effect. The mouthrinse, Oralclen $s^{\mathrm{TM}}$ ( $1 \%$ Citrox) demonstrated a slightly higher antimicrobial activity than mouthrinse Citrox $(1 \%) /$ Hyaluronic acid $(0.2 \%)^{\circledR}$. Importantly however, previous studies have demonstrated that $0.2 \%$ hyaluronan-containing gel provides benefit as an adjunct to scaling and root planning (SRP) in chronic periodontitis patients leading to a significant improvement in gingival parameters [34].

Given the reported problems of several over-the-counter mouthrinses, such as staining of enamel, burning sensation, alterations in taste, and the presence of an alcohol component $[30,35,36]$, there is a need for continual development of effective mouthrinses to aid oral hygiene regimes. As a result, natural compounds such as those incorporated into Citrox may be suitable alternatives. Further more, by combining Citrox with other supplements as shown in this preliminary study, enhanced antimicrobial effects against common oral pathogens can be obtained. These findings support further investigation into Citrox as a potential future preparation for oral care products and potentially other clinical areas where biofilms need to be prevented.

\section{List of abbreviations}

MBEC: Minimum biofilm eradication concentration

MIC: Minimum inhibitory concentration

FAA: Fastidious anaerobe agar

FAB: Fastidious anaerobe broth

BA: Blood agar

BHI: Brain heart infusion broth

SDA: Sabouraud Dextrose Agar

SAB: Sabouraud Broth

PBS: Phosphate buffered saline

MRSA: Methicillin-resistant Staphylococcus aureus

\section{Competing interests}

The authors declare that they have no competing interests.

\section{Acknowledgement}

The authors are grateful to OralDent Ltd UK for

the provision of all test antimicrobials.

Publication history

Editor: Celine Vidaillac, Clinical and Epidemiological Investigation Center, Luxembourg.

EIC: Todd R. Callaway, U.S. Department of Agriculture, USA.

Received: 24-Jul-2013 Revised: 22-Aug-2013

Accepted: 26-Sep-2013 Published: 04-Oct-2013

\section{References}

1. Rodrigues JA, Lussi A, Seemann R and Neuhaus KW. Prevention of crown and root caries in adults. Periodontol 2000. 2011; 55:231-49. | Article | PubMed 
Malic et al. Microbiology Discovery 2013,

2. Petersen $P E$ and Ogawa $H$. The global burden of periodontal disease: towards integration with chronic disease prevention and control. Periodontol 2000. 2012; 60:15-39. | Article | PubMed

3. Petersen PE. The World Oral Health Report 2003: continuous improvement of oral health in the 21st century--the approach of the WHO Global Oral Health Programme. Community Dent Oral Epidemiol. 2003; 31 Suppl 1:3-23. | Article | PubMed

4. Petersen PE and Baehni PC. Periodontal health and global public health Periodontol 2000. 2012; 60:7-14. | Article | PubMed

5. Watt RG and Petersen PE. Periodontal health through public health--the case for oral health promotion. Periodontol 2000. 2012; 60:147-55. I Article I PubMed

6. Meurman JH and Hamalainen P. Oral health and morbidity--implications of oral infections on the elderly. Gerodontology. 2006; 23:3-16. | Article I PubMed

7. Dann $\mathrm{AB}$ and Hontela $\mathrm{A}$. Triclosan: environmental exposure, toxicity and mechanisms of action. J App/ Toxicol. 2011; 31:285-311. | Article | PubMed

8. Suller MT and Russell AD. Triclosan and antibiotic resistance in Staphylococcus aureus. J Antimicrob Chemother. 2000; 46:11-8. | Article I PubMed

9. Lubarsky HV, Gerbersdorf SU, Hubas C, Behrens S, Ricciardi F and Paterson DM. Impairment of the bacterial biofilm stability by triclosan. PLoS One. 2012; 7:e31183. | Article | PubMed Abstract | PubMed Full Text

10. Brown J, Bernot MJ and Bernot RJ. The influence of TCS on the growth and behavior of the freshwater snail, Physa acuta. J Environ Sci Health $A$ Tox Hazard Subst Environ Eng. 2012; 47:1626-30. | Article | PubMed

11. Cortez FS, Seabra Pereira CD, Santos AR, Cesar A, Choueri RB, Martini Gde $A$ and Bohrer-Morel MB. Biological effects of environmentally relevant concentrations of the pharmaceutical Triclosan in the marine mussel Perna perna (Linnaeus, 1758). Environ Pollut. 2012; 168:145-50. | Article | PubMed

12. Bagis B, Baltacioglu E, Ozcan M and Ustaomer S. Evaluation of chlorhexidine gluconate mouthrinse-induced staining using a digital colorimeter: an in vivo study. Quintessence Int. 2011; 42:213-23. | Article I PubMed

13. Hooper SJ, Lewis MA, Wilson MJ and Williams DW. Antimicrobial activity of Citrox bioflavonoid preparations against oral microorganisms. $\mathrm{Br}$ Dent J. 2011; 210:E22. | Article | PubMed

14. Verkaik MJ, Busscher HJ, Jager D, Slomp AM, Abbas F and van der Mei $\mathrm{HC}$. Efficacy of natural antimicrobials in toothpaste formulations against oral biofilms in vitro. J Dent. 2011; 39:218-24. | Article | PubMed

15. Aqil F, Ahmad I and Owais M. Evaluation of anti-methicillin-resistant Staphylococcus aureus (MRSA) activity and synergy of some bioactive plant extracts. Biotechnol J. 2006; 1:1093-102. | Article | PubMed

16. Nakagawa H, Takaishi $Y$, Tanaka N, Tsuchiya K, Shibata H and Higuti T. Chemical constituents from the peels of Citrus sudachi. J Nat Prod. 2006; 69:1177-9. | Article | PubMed

17. Oliveira AC, Shinobu CS, Longhini R, Franco SL and Svidzinski TI. Antifungal activity of propolis extract against yeasts isolated from onychomycosis lesions. Mem Inst Oswaldo Cruz. 2006; 101:493-7. | Article | PubMed

18. Tait S, Salvati AL, Desideri N and Fiore L. Antiviral activity of substituted homoisoflavonoids on enteroviruses. Antiviral Res. 2006; 72:252-5. I Article I PubMed

19. Pilloni A, Annibali S, Dominici F, Di Paolo C, Papa M, Cassini MA and Polimeni A. Evaluation of the efficacy of an hyaluronic acid-based biogel on periodontal clinical parameters. A randomized-controlled clinical pilot study. Ann Stomatol (Roma). 2011; 2:3-9. | PubMed Abstract PubMed Full Text

20. Termeer C, Benedix F, Sleeman J, Fieber C, Voith U, Ahrens T, Miyake $\mathrm{K}$, Freudenberg M, Galanos C and Simon JC. Oligosaccharides of Hyaluronan activate dendritic cells via toll-like receptor 4. J Exp Med. 2002; 195:99-111. | Article | PubMed Abstract | PubMed Full Text
21. Sullivan DJ, Westerneng TJ, Haynes KA, Bennett DE and Coleman DC. Candida dubliniensis sp. nov.: phenotypic and molecular characterization of a novel species associated with oral candidosis in HIV-infected individuals. Microbiology. 1995; 141 ( Pt 7):1507-21. | Article I PubMed

22. Petersen $\mathrm{PE}$, Bourgeois D, Ogawa H, Estupinan-Day S and Ndiaye $C$. The global burden of oral diseases and risks to oral health. Bull World Health Organ. 2005; 83:661-9. | Article | PubMed Abstract | PubMed Full Text

23. Cowan, M.M. Plant Products as Antimicrobial Agents. Clinical Microbiology Reviews. 1999; 12:564-582. | Article

24. Moyle J.R, et al. Palatability of tannin-rich sericea lespedeza fed to broilers. The Journal of Applied Poultry Research. 2012; 21:891-896. | Article

25. Miloš Nikoli, Tatjana Markovi, Dejan Markovi, Tamara Peri, Jasmina Glamolija, Dejan Stojkovi and Marina Sokovi. Screening of antimicrobial and antioxidant activity of commercial Melaleuca alternifolia (tea tree) essential oils. Journal of Medicinal Plants Research. 2012; 6:3852-3858. I Pdf

26. Papadopoulos CJ, Carson CF, Hammer KA and Riley TV. Susceptibility of pseudomonads to Melaleuca alternifolia (tea tree) oil and components. $J$ Antimicrob Chemother. 2006; 58:449-51. | Article | PubMed

27. Sreenivasan $P$ and Gaffar $A$. Antiplaque biocides and bacterial resistance: a review. J Clin Periodontol. 2002; 29:965-74. | Article | PubMed

28. Clatworthy AE, Pierson E and Hung DT. Targeting virulence: a new paradigm for antimicrobial therapy. Nat Chem Biol. 2007; 3:541-8. | Article | PubMed

29. Palombo EA. Traditional medicinal plant extracts and natural products with activity against oral bacteria: potential application in the prevention and treatment of oral diseases. Evid Based Complement Alternat Med. 2011; 2011:680354. | Article | PubMed Abstract | PubMed Full Text

30. Ramage G, Jose A, Coco B, Rajendran R, Rautemaa R, Murray C, Lappin $\mathrm{DF}$ and Bagg J. Commercial mouthwashes are more effective than azole antifungals against Candida albicans biofilms in vitro. Oral Surg Oral Med Oral Pathol Oral Radiol Endod. 2011; 111:456-60. | Article | PubMed

31. Shapiro S, Giertsen E and Guggenheim B. An in vitro oral biofilm model for comparing the efficacy of antimicrobial mouthrinses. Caries Res. 2002; 36:93-100. | Article | PubMed

32. Tseng BS, Zhang W, Harrison JJ, Quach TP, Song JL, Penterman J, Singh PK, Chopp DL, Packman Al and Parsek MR. The extracellular matrix protects Pseudomonas aeruginosa biofilms by limiting the penetration of tobramycin. Environ Microbiol. 2013. | Article | PubMed

33. Donlan RM and Costerton JW. Biofilms: survival mechanisms of clinically relevant microorganisms. Clin Microbiol Rev. 2002; 15:167-93. | Article | PubMed Abstract | PubMed Full Text

34. Gontiya $G$ and Galgali SR. Effect of hyaluronan on periodontitis: A clinical and histological study. J Indian Soc Periodontol. 2012; 16:184-92. | Article | PubMed Abstract | PubMed Full Text

35. Conway D. Oral health, mouthwashes and cancer--what is the story? Evid Based Dent. 2009; 10:6-7. I Article | PubMed

36. La Vecchia C. Mouthwash and oral cancer risk: an update. Oral Oncol. 2009; 45:198-200. | Article | PubMed

\section{Citation:}

Malic S, Emanuel C, Lewis MAO and Williams DW. Antimicrobial activity of novel mouthrinses against planktonic cells and biofilms of pathogenic microorganisms. Microbiol Discov. 2013; 1:11. http://dx.doi.org/10.7243/2052-6180-1-11 